\title{
Observed Total Body Clearance Rate
}

National Cancer Institute

\section{Source}

National Cancer Institute. Observed Total Body Clearance Rate. NCI Thesaurus. Code C85773.

The observed total body clearance for intravascular administration. 